\title{
A systematic review on prevalence, risk factors, clinical diagnosis and medical management of dry eye disease in the Arab population
}

\begin{tabular}{|c|c|}
\hline \multicolumn{2}{|c|}{$\begin{array}{l}\text { Authors: } \\
\text { Mohammed A. Aljarousha }{ }^{1} \\
\text { Noor E. Badarudin } 1 \\
\text { Mohd Z. Che Azemin } \\
\text { Yousef Aljeesh } \\
\text { Amer Abuimara }{ }^{2}\end{array}$} \\
\hline \multicolumn{2}{|c|}{$\begin{array}{l}\text { Affiliations: } \\
\text { 'Department of Optometry } \\
\text { and Visual Science, Kulliyyah } \\
\text { of Allied Health Sciences, } \\
\text { International Islamic University } \\
\text { Malaysia, Bandar Indera } \\
\text { Mahkota, Kuantan, Pahang, } \\
\text { Malaysia }\end{array}$} \\
\hline \multicolumn{2}{|c|}{$\begin{array}{l}{ }^{2} \text { Department of Optometry, } \\
\text { Faculty of Health Science, } \\
\text { Islamic University of Gaza, } \\
\text { Palestine, Occupied } \\
\text { Palestinian Territory }\end{array}$} \\
\hline \multicolumn{2}{|c|}{$\begin{array}{l}{ }^{3} \text { College of Nursing, Islamic } \\
\text { University of Gaza, Palestine, } \\
\text { Occupied Palestinian Territory }\end{array}$} \\
\hline \multicolumn{2}{|c|}{$\begin{array}{l}\text { Corresponding author: } \\
\text { Mohammed Aljarousha, } \\
\text { mjaroosha@iugaza.edu.ps }\end{array}$} \\
\hline $\begin{array}{l}\text { Dates: } \\
\text { Received: } 28 \\
\text { Accepted: } 29 \\
\text { Published: } 03\end{array}$ & $\begin{array}{l}\text { une } 2020 \\
\text { Oct. } 2020 \\
\text { Feb. } 2021\end{array}$ \\
\hline \multicolumn{2}{|c|}{$\begin{array}{l}\text { How to cite this article: } \\
\text { Aljarousha MA, Badarudin NE, } \\
\text { Che Azemin MZ, Aljeesh Y, } \\
\text { Abuimara A. A systematic } \\
\text { review on prevalence, risk } \\
\text { factors, clinical diagnosis and } \\
\text { medical management of dry } \\
\text { eye disease in the Arab } \\
\text { population. Afr Vision Eye } \\
\text { Health. 2021;80(1), a591. } \\
\text { https://doi.org/10.4102/ } \\
\text { aveh.v80i1.591 }\end{array}$} \\
\hline \multicolumn{2}{|c|}{$\begin{array}{l}\text { Copyright: } \\
\text { ( 2021. The Author(s). } \\
\text { Licensee: AOSIS. This work } \\
\text { is licensed under the } \\
\text { Creative Commons } \\
\text { Attribution License. }\end{array}$} \\
\hline \multicolumn{2}{|l|}{ Read online: } \\
\hline 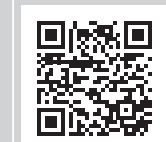 & $\begin{array}{l}\text { Scan this QR } \\
\text { code with your } \\
\text { smart phone or } \\
\text { mobile device } \\
\text { to read online. }\end{array}$ \\
\hline
\end{tabular}

Background: Dry eye (DE) is a multifactorial disorder that can influence tear production, functional visual acuity and ultimately increase the osmolarity of the tear film. The prevalence of DE ranges from $7 \%$ to $33 \%$ across the world. However, to the best of our knowledge, the prevalence range of DE in Arab countries is not precisely documented in the literature.

Aim: The aim of this article was to determine the prevalence range of DE, investigate the major risk factors of DE and identify the clinical diagnosis and medical management of DE.

Method: In this study, only English language articles from 2017 to 2020 were selected. There were 52 articles on prevalence, risk factors, clinical diagnosis and medical management of DE in the Arab population.

Results: The prevalence of DE in the Arab population varies in reports, from $10 \%$ in the United Arab Emirates (Dubai) to 69\% in Palestine (West Bank). Gender difference (DE more in women), wearing of contact lenses, diabetes mellitus and glaucoma were all known to intensify the symptoms of DE. Lastly, there are two approaches to reduce DE in the Arab population, namely, pharmacologic and non-pharmacologic methods.

Conclusion: The prevalence of DE in the Arab population was relatively high. In addition, the ocular surface disease index is one of the most common tools for the diagnosis of DE, whilst tear break-up time test is the common clinical test used in the Arab reports. Lastly, the most common treatment for DE is artificial tears.

Keywords: dry eye; artificial tears; contact lenses; glaucoma; Arab population.

\section{Background}

Dry eye (DE) is known as a multifactorial disease of the tears and ocular surface that results in symptoms such as discomfort and visual disturbance. In addition, profile tear film (TF) instability with possible damage to the ocular surface, which is characterised by increased osmolarity of the TF and inflammation of the ocular surface, is also observed. ${ }^{1,2}$ More so, researchers have postulated that DE is a specific pathology caused by diverse aetiologies.,4 According to Farrand et al., ${ }^{3}$ the pathology condition is also termed keratoconjunctivitis sicca (KCS) or dysfunctional tear syndrome (DTS) that results in a significant burden for both patients and ophthalmologists. Previous data have shown that the prevalence of DE ranges from $7 \%$ to $33 \%$ across the world. ${ }^{6,7}$ Researchers likewise suggested that the rates of DE vary widely from one population to another because of different definitions, race diversity, types of clinical diagnostic test used, lifestyle, specific regions and age range. ${ }^{8,9,10,11}$ Therefore, the exact percentage of DE is not accurately estimated worldwide. ${ }^{12}$ Cases with positive DE signs and clinical symptoms often result in impairment militating against achieving a productive lifestyle, social living and even standard level of education. ${ }^{13,14}$

Gender (more particularly women), advancing age, wearing of contact lenses (CLs), refractive surgery, smoking, visual display terminal (VDT) or extended smartphone use, watching TV and diabetes mellitus (DM) are known to be risk factors of DE that have been identified in extensive previous reports. $6,7,10,11,15,16$ Postmenopausal oestrogen therapy, vitamins A and D deficiency, antihistamines, eye diseases such as pterygium, blinking disorders and different educational and socio-economic status also exaggerate DE symptoms. ${ }^{17,18,19,20,21}$ Consequently, the treatment of this condition remains fairly problematic because of the lack of correlation between clinical symptoms and clinical diagnostic tests. ${ }^{16,22}$ 
Previous studies have reported that the prevalence of DE ranges from $8.7 \%$ to $32 \%$ in the Middle East. ${ }^{23,24}$ However, to the best of our knowledge, the prevalence range of DE in Arab countries is not currently available in the literature. Thus, the present study is the first to perform a systematic review to investigate the prevalence, risk factors, clinical diagnosis, influencing factors and medical management of DE disease specifically in Arab countries within four seasons, namely, less rainfall, cold temperature in winter, hot temperature and high humidity in summer.

\section{Methodology}

In this study, all search keywords were carried out with Boolean operators (OR/AND). Main keywords such as prevalence $\mathrm{OR}$ incidence $\mathrm{OR}$ rate $\mathrm{OR}$ frequency $\mathrm{OR}$ proportion OR epidemiology OR distribution OR major risk OR influencing factors OR symptoms OR questionnaires OR signs OR clinical tests and DE disease OR syndrome OR disorder were searched on Google Scholar and PubMed databases from June 2017 to June 2020. Furthermore, other search terms included treatment OR management and DTS OR xerophthalmia OR KCS OR keratitis sicca and pharmacologic OR non-pharmacologic approaches and in Arab countries (Saudi Arabia OR Palestine OR Kuwait OR Egypt OR Algeria OR Bahrain) in this investigation (see Figure 1). Admittedly, the information about the prevalence, risk factors, clinical diagnosis and medical management of DE in the Arab population were not available in the Cochrane, KoreaMed and Elsevier databases. This could be one of the limitations of this study. Another possible drawback of this systematic review is that only English language articles published from 2017 to 2020 were selected. The DE started to be referred to as a multifactorial disorder in 2017. ${ }^{2}$ However, meta-analysis reports conducted by Jüni et al. ${ }^{25}$ and Egger et al. ${ }^{26}$ postulated a higher quality of the methodology issues in the English

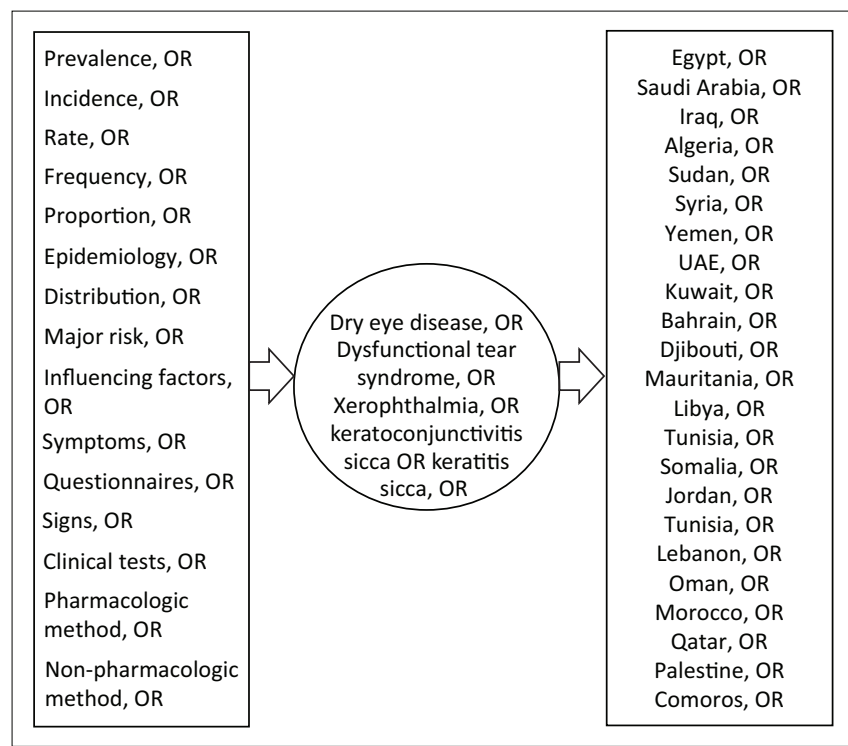

FIGURE 1: Search mode: Main keywords. language reviews compared with non-English language publications. The same group of authors also found that English language journals had larger sample sizes and highly reliable outcomes than for other language articles. Case series, case reports and control studies including the TF biochemistry, immunological picture of primary Sjogren's syndrome (SS), homeostasis of the TF, ocular surface inflammation and graft disease were excluded. Then, the following data were extracted from the articles or abstracts that met our inclusion criteria: year of publication, name of first investigator and co-workers, study design, country or area of study, range age or mean age, crude prevalence (\%), diagnostic criteria, risk factors and medical management. This enhances and helps to generalise the results of the study and improve internal validity. There were 52 articles and/or abstracts for DE disease in the Arab population in the different databases. However, there were very scarce cohort follow-up reports that aim to identify the treatment of DE disease and variation in the time of measurement of tear break-up time (TBUT) test and tear meniscus height. This is also a limitation of the study. All systematic reviews had a potential drawback, which is the tendency for publishing the manuscript's positive results. This is another limitation of the study. The flow chart of this study is presented in Figure 2.

\section{Ethical consideration}

This article followed all ethical standards for research without direct contact with human or animal subjects.

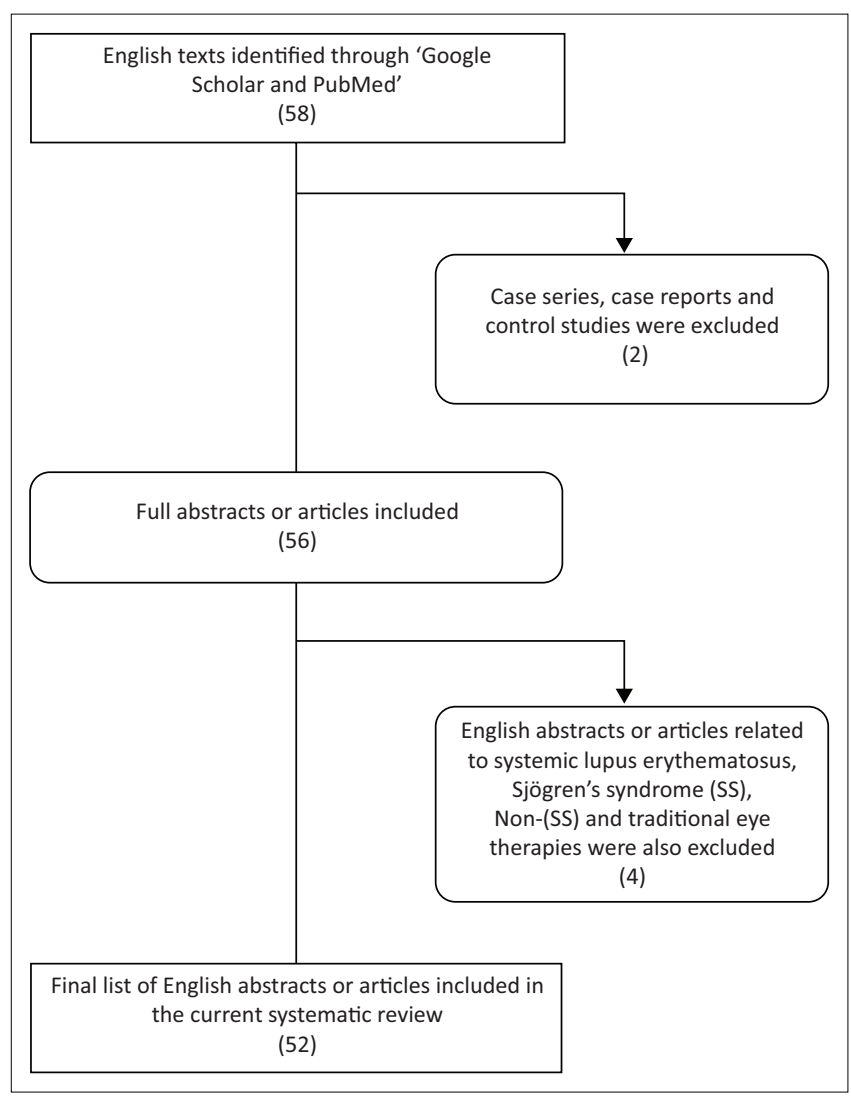

FIGURE 2: Flow chart of the current systematic review. 


\section{Results}

\section{Prevalence of dry eye}

The latest development is a prevalence study of DE in Riyadh district based on a prospective study by utilising the McMonnies' DE questionnaire. ${ }^{12}$ A similar study reported that the overall prevalence of DE was $35.9 \%$ in cases $\geq 40$ years of age (Table 1 ). Another study, which observed the frequency of DE in the Northern Region of Saudi Arabia, was performed by Alsweilem et al. ${ }^{19}$ Their sample consisted of 384 teenagers, which was investigated at 3 months for data collection. The rate of DE in the report was assessed by a predesigned questionnaire. Their results showed that approximately $36.5 \%$ of the teenager participants had clinical symptoms. A less recent report that also postulated to determine the prevalence of clinical symptoms associated with risk factors in the King Abdulaziz Specialist Hospital (Taif) was adopted by Alzahrani et al. ${ }^{20}$ In that report, the identified risk factors impacting ocular surface disease index (OSDI) included arthritis, hypercholesterolaemia and Lasik surgery. The frequency of DE symptoms in Al-Ahsa, Saudi Arabia was $32.1 \%$, with a higher percentage in subjects $>56$ years of age and more predominant in women compared with men, and with the highest percentage amongst smokers and diabetic patients. ${ }^{23}$ Likewise, Alharbi and co-workers revealed a higher frequency of DE in coastal population of eastern province, Saudi Arabia (62.4\%) compared with the previous clinical report. ${ }^{23}$ The same group used the OSDI to assess DE disease. $^{27}$

Furthermore, in a cross-sectional study of DE cases in Egypt, the prevalence of DE disease was $6.8 \%{ }^{28}$ It was carried out in Behira, Egypt, with an average age of 40 years for participants. Another clinic-based study by Rashwan et al. demonstrated that the percentage of DE was $12.8 \%$ in the Al-Zahraa University Hospital in Egypt. ${ }^{29}$ In addition, Iqbal et al. found the prevalence of DE subjectively in those with computer vision syndrome (CVS). ${ }^{30}$ The same group of researchers demonstrated that the rate of DE was $28 \%$ amongst the medical students in Sohag University, Egypt. More recently, Shanti et al. postulated that $69 \%$ of subjects in northern West Bank of Palestine had positive DE symptoms and signs. ${ }^{31}$ Their investigation of DE was performed in 769 subjects recruited through a random sampling method. Similarly, the prevalence of DE disease was reported to be as high as $52 \%$ in a study of DE in Jordan involving 802 participants based on DE questionnaires. ${ }^{36}$

According to Younis et al., 27.2\% of patients with rheumatoid arthritis had DE symptoms. ${ }^{32}$ Ali et al..$^{33}$ found that the overall prevalence of DE symptoms was 10\% in 120 Dubai households in UAE. One such report was by Zbiba et al. who looked at the DE disease and its relationship with Acanthamoeba keratitis (AK) amongst the patients of Taher Maamouri Hospital in Tunisia. They found four DE syndrome cases out of $14 \mathrm{AK}^{34}$

One such report was by Omran et al. who looked at the DE disease and its relationship with pterygium amongst the patients of Benghaz eye hospital in Libya. ${ }^{17}$ They evaluated 35 subjects aged 26 years and older and found using Schirmer's tear test (STT) that the prevalence of DE was $40 \%$. In a clinical study of an asymptomatic DE in the Lebanese population, with subjects older than 18 years, the prevalence was found to be $36.4 \% .{ }^{35}$ The symptomatic DE assessment by the OSDI questionnaire was adopted in some studies.

\section{Clinical diagnosis of dry eye}

Routinely, dry eye questionnaires (DEQs) are employed for examining the natural history of the disease and in population-based studies. ${ }^{3}$ Ocular symptoms are the major concern for patients with $\mathrm{DE},{ }^{1}$ which signifies the importance of the application of the appropriately validated

TABLE 1: Summary of Arab studies on the prevalence of dry eyes from 2017 to 2020.

\begin{tabular}{|c|c|c|c|c|c|c|c|}
\hline Authors & $\begin{array}{l}\text { Sample } \\
\text { size }(n)\end{array}$ & Country/area & Age range (years) & Mode of diagnosis of DEs & $\begin{array}{c}\text { Crude } \\
\text { prevalence }(\%)\end{array}$ & $\begin{array}{l}\text { Associated with } \\
\text { old age }\end{array}$ & $\begin{array}{l}\text { Associated with } \\
\text { female gender }\end{array}$ \\
\hline Yasir et al. ${ }^{12}$ & 400 & Saudi Arabia (Riyadh) & $\geq 40$ & McMonnies symptom questionnaire & 35.9 & NS & $\mathrm{s}$ \\
\hline Alsweilem et al..$^{20}$ & 384 & Saudi Arabia (Arar) & $\geq 15$ & Predesigned questionnaire & 36.5 & NS & NS \\
\hline Alzahrani et al. ${ }^{21}$ & 482 & Saudi Arabia (Taif) & $6-86$ & OSDI questionnaire & 41.7 & S & NS \\
\hline Alshamrani et al..$^{23}$ & 1224 & Saudi Arabia (Al-Ahsa) & $16-78$ & Six-item questionnaire & 32.1 & S & S \\
\hline Alharbi et al. ${ }^{27}$ & 384 & $\begin{array}{l}\text { Saudi Arabia (Eastern } \\
\text { province) }\end{array}$ & $6-40$ & OSDI questionnaire & 62.4 & S & NS \\
\hline Mourad et al. ${ }^{28}$ & 6252 & Egypt (Beheira) & $1-88$ & $\mathrm{FL} / \mathrm{S}$ and TBUT & 6.8 & N/A & N/A \\
\hline Rashwan et al. ${ }^{29}$ & 500 & Egypt (Cairo) & $14-81$ & TBUT, STT, STT and MGD & 22.8 & N/A & N/A \\
\hline lqbal et al. ${ }^{30}$ & 100 & Egypt (Sohag) & $18-24$ & CVS questionnaire & 28 & N/A & N/A \\
\hline Shanti et al. ${ }^{31}$ & 769 & Palestine (West Bank) & $18-90$ & OSDI, FL/S, TBUT and STT & 69 & s & S \\
\hline Haddad et al. ${ }^{36}$ & 802 & Jordan (Irbid) & $18-80$ & $\begin{array}{l}\text { Presence of one or more dry eye } \\
\text { symptoms }\end{array}$ & 52 & NS & S \\
\hline Younis et al. ${ }^{32}$ & 103 & Iraq (Bagdad) & $23-60$ & $\begin{array}{l}\text { Presence of one or more dry eye } \\
\text { symptoms, STT }\end{array}$ & 27.2 & NS & NS \\
\hline Ali et al. ${ }^{33}$ & 770 & UAE & $\geq 20$ & $\begin{array}{l}\text { One or more symptoms often or } \\
\text { most time }\end{array}$ & 10 & N/A & N/A \\
\hline Zbiba et al. ${ }^{34}$ & 230 & Tunisia & $\geq 20$ & $\mathrm{FL} / \mathrm{S}, \mathrm{TBUT}$ & 28.5 & N/A & N/A \\
\hline Sherry et al..$^{35}$ & 602 & Lebanon & $\geq 18$ & OSDI & 36.4 & s & NS \\
\hline Omran et al. ${ }^{17}$ & 35 & Libya (Benghaz) & $\geq 26$ & STT-1 and TBUT & 40 & N/A & S \\
\hline
\end{tabular}

OSDI, ocular surface disease index; TBUT, tear break up time test; STT, Schirmer's tear test; FL/S, fluorescein staining; S, statistically significant association; NS, statically insignificant association; DEs, dry eyes; MGD, meibomian gland dysfunction; CVS, computer vision syndrome; N/A, not applicable. 
questionnaires in defining the issue. ${ }^{2}$ Several DEQs have been included in Arab studies, such as the OSDI questionnaire,

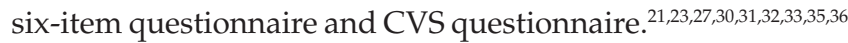
However, the OSDI is one of the most common tools for the diagnosis of DE syndrome and other ocular surface diseases, such as allergic conjunctivitis and blepharitis, ${ }^{37}$ in the Arab population. This questionnaire consists of 12 items that evaluate three subscales of DE consisting of experiencing symptoms of ocular irritation in the eyes, change in functional quality of vision and environmental factor stimuli of DE. ${ }^{1}$

Meanwhile, it was also reported that a number of clinical tests could be applied to diagnose DE in the Arab population reports. Examples include the TBUT, STT, meibomian gland dysfunction (MGD), tear meniscus height, lid-to-globe apposition, blink abnormalities, lissamine green staining, rose Bengal staining and the corneal/conjunctival fluorescein staining. ${ }^{17,28,29,31,32,34,38}$ However, the most common clinical test used in the Arab reports is the TBUT. The period from the last blink to the appearance of random dark spots and streaks in tears was recorded as TBUT.

\section{Medical management of dry eye}

Dry eye disorder (DED) is reduced in the Arab population by many approaches, such as pharmacologic and nonpharmacologic methods. ${ }^{16,19,39}$ Thereare several pharmacologic methods, which include tear supplementation, tear retention, tear stimulation and anti-inflammatory agents. ${ }^{40}$ On the other hand, there are many possible non-pharmacologic approaches regarding the management of DE pathology. These include avoidance of exacerbating factors and eyelid hygiene. ${ }^{41,42,43}$

Many tear supplements can be applied to manage the DE syndrome, but the most common treatment of DE in Arab populations includes artificial tears ${ }^{44}$ Asbell ${ }^{45}$ found that the use of artificial tears in mild to moderate DE disease was effective. Patients with moderate to severe disease often combine artificial tears with other forms of treatments. ${ }^{46}$ The autologous serum tear secreted by the patient has also been used in the management of severe DE syndrome. ${ }^{47}$

There are four approaches for tear retention, namely, punctal plugs, moisture spectacles/goggles, therapeutic CLs and tarsorrhaphy. ${ }^{48,49}$ Whilst tear stimulation, for instance, oral cholinergic agents such as pilocarpine or cevimeline (used off-label for aqueous-deficient DED). ${ }^{50,51}$

Another form of treatment is the use of anti-inflammatory agents. The anti-inflammatory agents can be divided into three main medications, which include topical corticosteroids, oral tetracyclines and topical cyclosporine. ${ }^{39,52}$ On the other hand, other therapies such as nutritional supplements (essential fatty acids), mucolytics (topical acetylcysteine, used off-label in DED with filamentary keratitis) and topical vitamin A (off-label and controversial, but possibly useful in severe DED with squamous metaplasia or ocular surface keratinisation) have also been explored..$^{52,53,54}$

\section{Discussion}

There is high prevalence of DED in the Arab studies compared with other parts of the world. This might be because of the high percentage of rheumatoid arthritis, DM and the use of age-related systemic and topical medications in the elderly population. . $11,23,27,31,35^{2}$

Alzahrani et al. ${ }^{21}$ and several other researchers (Sherry et al. ${ }^{35}$; Shanti et al. ${ }^{31}$ ) have reported a significant association between TF harm and increase in age (see Table 2). This may be because of the high percentage of rheumatoid arthritis, DM and the use of age-related systemic and topical medications, which may lead to deterioration of TF intact. ${ }^{5,12}$ Furthermore, gender is another factor that has been documented to influence TF profile. ${ }^{6,7}$ Arab data found altered rate of tear production in women as compared to men, particularly after

TABLE 2: Risk factors associated with dry eyes amongst the Arab population from 2017 to 2020

\begin{tabular}{|c|c|}
\hline Risk factors & References \\
\hline Increase in age & Alzahrani et al. ${ }^{21}$; Alshamrani et al. ${ }^{23}$; Alharbi et al. ${ }^{27}$; Shanti et al. ${ }^{31}$; Sherry et al. ${ }^{35}$ \\
\hline Female gender & Yasir et al. ${ }^{12}$; Alshamrani et al. ${ }^{23}$; Shanti et al. ${ }^{31}$; Haddad et al. ${ }^{36}$; Shadia et al. ${ }^{58}$ \\
\hline CLs uses & Alsweilem et al. ${ }^{20}$; Sharief ${ }^{37}$ \\
\hline Refractive operations and cataract operation & Alsweilem et al. ${ }^{20}$; Alzahrani et al. ${ }^{23}$; Sharief ${ }^{37}$ Kalakattawi et al. ${ }^{59}$ \\
\hline Glaucoma, medications, topical glaucoma eye drops and biological drugs & Yasir et al. ${ }^{12}$; Younis and Al-Quzweeni ${ }^{32}$ \\
\hline Using antidepressants drug and/or multivitamins supplements & Alharbi et al. ${ }^{27}$ \\
\hline $\begin{array}{l}\text { Acanthamoeba keratitis, pterygium, blepharitis, spring catarrh, MGD, allergic } \\
\text { conjunctivitis and keratoconus }\end{array}$ & Omran et al. ${ }^{17} ;$ Alsweilem et al. ${ }^{20} ;$ Zbiba et al..$^{34} ;$ Sharief ${ }^{37} ;$ Awad et al. ${ }^{60} ;$ El Sawy et al. ${ }^{61}$ \\
\hline Rheumatoid arthritis, thyroid diseases and high total cholesterol levels & Alzahrani et al..$^{21}$; Alharbi et al..$^{27}$; Younis ${ }^{32}$; Abusharaha et al. ${ }^{62}$; ALANAZI ${ }^{63}$ \\
\hline Diabetes mellitus & $\begin{array}{l}\text { Alshamrani et al. }{ }^{23} \text {; Alzahrani et al. } .^{21} \text {; Alharbi et al. }{ }^{27} \text {; Masmali et al. }{ }^{64} \text {; Kamel et al. }{ }^{65} \text {; El Sawy et al. }{ }^{61} \text {; } \\
\text { Kalakattawi et al. }{ }^{59} \text {; Elnour et al. }{ }^{66} \text {; Masmali et al. }{ }^{64}\end{array}$ \\
\hline Hypertension, dyslipidaemia and obesity & Safaa Bashir et al. ${ }^{67}$; Alghamdi ${ }^{68}$ \\
\hline Wider usage of the computer or smartphone or ATM & Baabdullah et al. ${ }^{11}$; Iqbal et al. ${ }^{30}$; Ghufran et al. ${ }^{56}$; Al Tawil et al. ${ }^{57}$; Kalakattawi et al. ${ }^{59}$; Ahmed et al. ${ }^{69}$ \\
\hline Smoking or passive smoking and high body mass index & Sherry et al. ${ }^{35}$; Khalil et al. ${ }^{70}$; Alanazi et al. ${ }^{71}$; Alanazi ${ }^{72}$ \\
\hline Vitamin A deficiency and vitamin D deficiency & Alanazi et al. ${ }^{19}$; Sharief ${ }^{37}$; Elagamy ${ }^{73}$ \\
\hline Degree of refractive error and occupation & Sharief ${ }^{37}$; Ahmed et al. ${ }^{38}$ \\
\hline Obstructive sleep apnoea and impact on CCT & Kalakattawi et al. ${ }^{59}$; Alharthi et al..$^{74}$; Ali et al..$^{75}$; Elnour et al. ${ }^{66}$ \\
\hline Indoor/outdoor occupation and urban area & Yasir et al. ${ }^{12}$; Alharbi et al. ${ }^{27}$; Sharief ${ }^{37}$; Fagehi et al. ${ }^{76}$ \\
\hline
\end{tabular}

CLs, contact lenses; MGD, meibomian gland dysfunction; CCT, central corneal thickness; ATM, automated teller machine. 
menopause, ${ }^{31,36}$ probably because of lower levels of sex hormones, which support sufficient lacrimal gland production, meibomian gland function, goblet cells density and normal tear flow. ${ }^{31,55}$ More so, previous reports from Saudi Arabia (Taif and Arar) discovered that DE symptoms were significantly higher in cases with refractive operation as compared with non-refractive operation..$^{21,23}$ On the same note, according to previous surveys, many ocular diseases such as blepharitis, glaucoma, MGD, keratoconus, spring catarrh, pterygium and allergic conjunctivitis have been identified as the risk factors of DED in the Arab population. ${ }^{12,16,17,37}$ In addition, numerous clinical reports have postulated a high frequency of clinical DE symptoms in patients applying topical glaucoma eye drops and biological drugs. ${ }^{12,32}$ Likewise, other reported risk factors associated with DTS in the Arab population include arthritis, DM, hypertension, vitamins A and D deficiency and thyroid disease. ${ }^{21,27,32,37}$ Khalil et al., Alanazi et al. and Sherry et al. have also postulated that DE symptoms significantly differed between smokers and non-smokers in Egypt, Saudi Arabia and Lebanon, respectively. Many reports have also shown a relationship between prolonged use of the computer or smartphone and intense symptoms. ${ }^{11,30,56,57}$ Risk factors of DE in the Arab countries are shown in Table 2.

Previous studies on the Arab population found a significant relationship between DE symptoms and positive clinical signs. ${ }^{17,29,31}$ This might be attributed to different DE surveys and types of clinical diagnostic tests used. For instance, Shanti et al. ${ }^{31}$ reported a strong association between intense symptoms and clinical diagnostic signs, whilst Yasir et al. ${ }^{12}$ reported a lack of association between the self-reported symptoms and positive DE signs.

\section{Conclusion}

The prevalence of DE in the Arab population varies in reports, from $10 \%$ in UAE to $69 \%$ in Palestine. Increase in age, gender difference (more in females), wearing of CLs, refractive operation, glaucoma, blepharitis, MGD, pterygium, spring catarrh and allergic conjunctivitis were all known to be related to DE in the Arab population. In addition, topical glaucoma eye drops, biological drugs, arthritis, thyroid disease, hypertension, DM, smoking or passive smoking, computer or smartphone, watching television and continuous reading were also reported to influence the DED prevalence. Furthermore, OSDI is one of the most common tools for the diagnosis of DE syndrome in the Arab population, whilst the most common clinical test used in the Arab reports is the TBUT. Some previous reports have found a lack of association between DE symptoms and signs. However, other studies have found a strong association between them. For treatment, tear supplements can be applied to manage the DE syndrome, and the most common treatment of DE in Arab populations is the use of artificial tears.

\section{Acknowledgements}

The authors would like to thank the Optometry Department of the Islamic University of Gaza.

\section{Competing interests}

The authors declare that there are no financial or personal relationships that may have inappropriately influenced them in writing this article.

\section{Authors' contributions}

This article forms part of a PhD of optometry research study undertaken by M.A.A. with N.E.B, M.Z.C.A., Y.A. and A.A. as the supervisor.

\section{Funding information}

This research received no specific grant from any funding agency in the public, commercial, or not-for-profit sectors.

\section{Data availability statement}

Data sharing is not applicable to this article.

\section{Disclaimer}

The views and opinions expressed in this article are those of the authors and do not necessarily reflect the official policy or position of any affiliated agency of the authors.

\section{References}

1. Craig JP, Nichols KK, Akpek EK, et al. TFOS DEWS II definition and classification report. Ocul Surf. 2017;15(3):276-283. https://doi.org/10.1016/j.jtos.2017. 05.008

2. Wolffsohn JS, Arita R, Chalmers R, et al. TFOS DEWS II diagnostic methodology report. Ocul Surf. 2017;15(3):539-574. https://doi.org/10.1016/j.jtos.2017. 05.001

3. Stapleton F, Alves M, Bunya VY, et al. TFOS DEWS II epidemiology report. Ocul Surf. 2017;15(3):334-365. https://doi.org/10.1016/j.jtos.2017.05.003

4. Bron AJ, De Paiva CS, Chauhan SK, et al. TFOS DEWS II pathophysiology report. Ocul Surf. 2017;15(3):438-510. https://doi.org/10.1016/j.jtos.2017.05.011

5. Farrand KF, Fridman M, Stillman IO, Schaumberg DA. Prevalence of diagnosed dry eye disease in the United States among adults aged 18 years and older. Am Ophthalmol. 2017;182:90-98. https://doi.org/10.1016/j.ajo.2017.06.033

6. Tan LL, Morgan P, Cai ZQ, Straughan RA. Prevalence of and risk factors for symptomatic dry eye disease in Singapore. Clin Exp Optom. 2015;98(1):45-53. https://doi.org/10.1111/cxo.12210

7. Abd Rahman A, Aljarousha M, Badarudin N, Che Azemin M, Awad K. Prevalence and risk factors of dry eye disease in Kuantan, Malaysia. Makara J Health Res. 2018;22(1):27-33. https://doi.org/10.7454/msk.v22i1.8749

8. Craig JP, Lim J, Han A, Tien L, Xue AL, Wang MTM. Ethnic differences between the Asian and Caucasian ocular surface: A co-located adult migrant population cohort study. Ocul Surf. 2019;17(1):83-88. https://doi.org/10.1016/j.jtos.2018. 09.005

9. Kim JS, Wang MTM, Craig JP. Exploring the Asian ethnic predisposition to dry eye disease in a pediatric population. Ocul Surf. 2019;17(1):70-77. https://doi. org $/ 10.1016 /$ j.jtos.2018.09.003

10. Dana R, Bradley JL, Guerin A, et al. Estimated prevalence and incidence of dry eye disease based on coding analysis of a large, all-age United States Health Care System. Am J Ophthalmol. 2019;202:47-54. https://doi.org/10.1016/j.ajo.2019. 01.026

11. Baabdullah AM, Abumohssin AG, Alqahtani YA, Nemri IA, Sabbahi DA, Alhibshi NM. The association between smartphone addiction and dry eye disease: A crosssectional study. J Nat Sci Med. 2019;2(2):81-85. https://doi.org/10.4103/JNSM. JNSM_51_18

12. Yasir ZH, Chauhan D, Khandekar R, Souru C, Varghese S. Prevalence and determinants of dry eye disease among 40 years and older population of Riyadh (except capital), Saudi Arabia. Middle East Afr J Ophthalmol. 2019;26(1):27-32. https://doi.org/10.4103/meajo.MEAJO_194_18

13. Kawashima M, Sano K, Takechi S, Tsubota K. Impact of lifestyle intervention on dry eye disease in office workers: A randomized controlled trial. J Occup Health. 2018;60(4):281-288. https://doi.org/10.1539/joh.2017-0191-OA

14. Lukcso D, Guidotti TL, Franklin DE, Burt A. Indoor environmental and air quality characteristics, building-related health symptoms, and worker productivity in a federal government building complex. Arch Environ Occup Health. 2016;71(2): 85-101. https://doi.org/10.1080/19338244.2014.965246 
15. Zhang S, Hong J. Risk factors for dry eye in Mainland China: A multi-center cross-sectional hospital-based study. Ophthalmic Epidemiol. 2019;26(6):393-399. https://doi.org/10.1080/09286586.2019.1632905

16. Alharbi OO, Beyari GM, Saber WA, et al. Etiology, prevalence, risk factors, and treatment of dry eye disease. Int J Med Develop Countr. 2020;4(1):137-142. https://doi.org/10.24911/IJMDC.51-1573612517

17. Omran OM, Bukhatwa SA. Association between pterygium and dry eye among patients in Benghazi, Libya. Libyan J Med Sci. 2020;4(2):80-83. https://doi.org/ 10.4103/LJMS.LJMS 62

18. Din NM, Sa'aid SHB, Shen LC, et al. Hormone replacement therapy and dry eye in post-menopausal women: Study in a tertiary centre in Malaysia. Int J Med Students. 2013;1(1):12-15. https://doi.org/10.5195/ijms.2013.14

19. Alanazi SA, Alfaifi AS, Abusharha A, et al. Effect of short-term oral vitamin D3 supplementation on tear film in dry eye subjects. Int J Ophthalmol Vis Sci. 2019;4(3):51-57. https://doi.org/10.11648/j.ijovs.20190403.13

20. Alsweilem M, Alenzi MK, Almutairi SN, Alanazy TA. Prevalence of eye dryness among the general population of the Northern Region of Saudi Arabia. Int Med Develop Countr. 2019;3(10):841-848. https://doi.org/10.24911/IJMDC.511562222687

21. Alzahrani A, Alhamyani A, Noor Kalakattawi R, et al. Prevalence of dry eye symptoms and its risk factors among patients of King Abdulaziz Specialist Hospital (Taif), Saudi Arabia. Saudi J Health Sci. 2017;6(3):140. https://doi.org/10.4103/ sjhs.sjhs_90_17

22. Roth Cl, Stanila A, Maniu I, Muntean AC. Dry eye: The relation between symptoms and diagnostic tests. SEA Pract Appl Sci. 2019;VII(20):125-130.

23. Alshamrani AA, Almousa AS, Almulhim AA, et al. Prevalence and risk factors of dry eye symptoms in a Saudi Arabian population. Middle East Afr J Ophthalmol. 2017;24(2):67-73. https://doi.org/10.4103/meajo.MEAJO_281_16

24. Hashemi $\mathrm{H}$, Khabazkhoob $\mathrm{M}$, Kheirkhah $\mathrm{A}$, et al. Prevalence of dry eye syndrome in an adult population. Clin Exp Ophthalmol. 2014;42(3):242-248. https://doi. org/10.1111/ceo.12183

25. Jüni P, Holenstein F, Sterne S, Bartlett C, Egger M. Direction and impact of language bias in meta-analyses of controlled trials: Empirical study. Int J Epidemiol. 2002;31(1):115-123. https://doi.org/10.1093/ije/31.1.115

26. Egger M, Zellweger-Zähner T, Schneider M, Junker C, Lengeler C, Antes G. Language bias in randomised controlled trials published in English and German. Lancet. 1997;350(9074):326-329.

27. Alharbi A, Alanazi N, Alhamad J, et al. Prevalence of symptomatic dry eye and its risk factors among coastal population in eastern province of Saudi Arabia. J Clin Exp Ophthalmol. 2018;9:34

28. Mourad MS, Rafat AR, Moustafa OAM, Hamid M. Prevalence of different eye diseases excluding refractive errors presented at the outpatient clinic in diseases excluding refractive errors presented at the outpatient clinic in
Beheira eye hospital. Egypt J Hosp Med. 2018;71(2):2484-2489. https://doi.org/ Beheira eye hospital.
10.12816/0045645

29. Rashwan A, Abo-Elkheir O, Metwally A. Pattern of eye diseases in ophthalmic outpatient clinic of Al-Zahraa University Hospital: An observational descriptive outpatient clinic of Al-Zahraa University Hospita:
study. Egypt J Hosp Med. 2019;77(1):4754-4759.

30. Iqbal M, El-Massry A, Elagouz M, Elzembely H. Computer vision syndrome survey among the medical students in Sohag University Hospital, Egypt. Ophthalmol Res. 2018;8(1):1-8. https://doi.org/10.9734/OR/2018/38436

31. Shanti Y, Shehada R, Bakkar MM, Qaddumi J. Prevalence and associated risk factors of dry eye disease in 16 Northern West bank towns in Palestine: A crosssectional study. BMC Ophthalmol. 2020;20:26. https://doi.org/10.1186/s12886019-1290-z

32. Younis HA, Al-Quzweeni ZYJ. Prevalence of dry eye disease in rheumatoid arthritis patients. World Fam Med. 2019;17(12):21-26. https://doi.org/10.5742/MEWFM 2019.93709

33. Ali MI. Prevalence and risk factors of poor indoor air quality and sick house syndrome symptoms in Dubai [homepage on the Internet]. The British University in Dubai (BUiD); 2019 [cited 2020 June 15]. Available from: https://bspace. buid.ac.ae/handle/1234/1380

34. Zbiba W, Abdesslem NB. Acanthamoeba keratitis: An emerging disease among microbial keratitis in the Cap Bon region of Tunisia. Exp Parasitol. 2018;192:42-45. https://doi.org/10.1016/j.exppara.2018.05.005

35. Sherry A, Aridi M, Ghach W. Prevalence and risk factors of symptomatic dry eye disease in Lebanon. Contact Lens Anterior Eye. 2019;43(4):355-358. https://doi org/10.1016/j.clae.2019.08.001

36. Haddad MF, Bakkar MM, Abdo N. Public awareness of common eye disease in Jordan. BMC Ophthalmol. 2017;17:177-183. https://doi.org/10.1186/s12886017-0575-3

37. Sharief AT. Relationship between dry eye syndrome and occupational categories. Sudanese J Ophthalmol. 2019;11(2):35-41. https://doi.org/10.4103/sjopthal. sjopthal_19_19

38. Youssef AA, Alahmadawy YA, Elmekkawy HE, Abdelrahman AM. Schirmer's test and tear breakup time in an Egyptian population sample: A hospital-based study. Delta J Ophthalmol. 2020;21(1):6-13.

39. Bragheeth MA, El-Kasaby MI. Topical corticosteroid drops in the management of dry eye. Egypt J Hosp Med. 2018;39(1):181-188.

40. Alanazi SA, Abusharha A, Fagehi R, et al. Assessment of the tear evaporation rate in chronic smokers using delfin vapometer. Int J Ophthalmol Vis Sci. 2019;4(2) 37-41.

41. Alanazi SA, El-Hiti GA, Al-Baloud AA, et al. Effects of short-term oral vitamin A supplementation on the ocular tear film in patients with dry eye. Clin Ophthalmol. 2019;13:599-604. https://doi.org/10.2147/OPTH.S198349
42. Masmali AM, Alotaibi AG, Alanazi SA, Fagehi R, Abusharaha A, El-Hiti GA. The acute effect of a single dose of green tea on the quality and quantity of tears in normal eye subjects. Clin Ophthalmol. 2019;13:605-610. https://doi.org/10.2147/ OPTH.S201127

43. Masmali AM, Alanazi SA, Almagren B, El-Hiti GA. Assessment of the tear film in normal eye subjects after consumption of a single dose of hot peppermint drink. Clin Optom. 2019;11:39-45. https://doi.org/10.2147/OPTO.S206904

44. Alanazi SA, Badawood YS, Aldawood MA, El-Hiti GA, Masmali AM. Effect of refresh plus ${ }^{\circledast}$ preservative-free lubricant eyedrops on tear ferning patterns in dry eye and normal eye subjects. Clin Ophthalmol. 2019;13:1011-1017. https://doi. org/10.2147/OPTH.S213365

45. Asbell PA. Increasing importance of dry eye syndrome and the ideal artificial tear: Consensus views from a roundtable discussion. Curr Med Res Opin 2006;22(11):2149-2157. https://doi.org/10.1185/030079906X132640

46. Ngo W, Srinivasan S, Houtman D, Jones L. The relief of dry eye signs and symptoms using a combination of lubricants, lid hygiene and ocular nutraceuticals. J Optom. 2017;10(1):26-33. https://doi.org/10.1016/j.optom.2016.05.001

47. Pan Q, Angelina A, Marrone M, Stark WJ, Akpek EK. Autologous serum eye drops for dry eye. Cochrane Database Syst Rev. 2017;2:CD009327. https://doi org/10.1002/14651858.CD009327.pub3

48. Farrant S. TFOS DEWS II - Part 3 management. Optician Select. 2018;2018(1):6858. https://doi.org/10.12968/opti.2018.1.6858

49. Weiss $M$, Fischer J, Neff T, Baenziger $O$. The effects of syringe plunger design on drug delivery during vertical displacement of syringe pumps. Anaesthesia. 2000;55:1094-1098. https://doi.org/10.1046/j.1365-2044.2000.01550.x

50. Liao Y, Zhang X, Liu Z. Topical tear stimulation - A new insight for dry eye therapy. Ann Eye Sci. 2017;2:1. https://doi.org/10.21037/aes.2016.12.04

51. Cha S, Kim HK, Kho HS, Park YS. The sustained effects on tear volume of pilocarpine hydrochloride in gelatin by hydrogel administered by an implant-mediated drug delivery system. Curr Drug Deliv. 2017;14(4):581-6. https://doi.org/10.2174/156 7201813666161013150648

52. AlHarkan DH. Management of vernal keratoconjunctivitis in children in Saud Arabia. Oman J Ophthalmol. 2020;13(1):3. https://doi.org/10.4103/ojo.OJO_ 263_2018

53. Askari G, Rafie N, Miraghajani M, Heidari Z, Arab A. Association between vitamin $D$ and dry eye disease: A systematic review and meta-analysis of observational $\mathrm{D}$ and dry eye disease: A systematic review and meta-analysis of observational
studies. Cont Lens Anterior Eye. 2020;43(5):418-425. https://doi.org/10.1016/j. studies. Cont Lens Ar
clae.2020.03.001

54. Shahat AS, Hassan WA, El-Sayed WM. N-Acetylcysteine and Safranal prevented the brain damage induced by hyperthyroidism in adult male rats. Nutr Neurosci. 2020. https://doi.org/10.1080/1028415X.2020.1743917

55. Bakkar MM, Shihadeh WA, Haddad MF, Khader YS. Epidemiology of symptoms of dry eye disease (DED) in Jordan: A cross-sectional non-clinical population-based study. Cont Lens Anterior Eye 2016;39(3):197-202. https://doi.org/10.1016/j. study. Cont Lens

56. Abudawood GA, Ashi HM, Almarzouki NK. Computer vision syndrome among undergraduate medical students in King Abdulaziz University, Jeddah, Saudi Arabia. J Ophthalmol. 2020;2020:2789376. https://doi.org/10.1155/2020/ 2789376

57. Al Tawil L, Aldokhayel S, Zeitouni L, Qadoumi T, Hussein S, Ahamed SS. Prevalence of self-reported computer vision syndrome symptoms and its associated factors among university students. Eur J Ophthalmol. 2020;30(1):189-195. https://doi. org/10.1177/1120672118815110

58. Mehaseb SH, Omran AAH, Gafer HA, Ahmed El Habashy Al. Assessing the effect of menopausal symptoms on women's quality of life. Egypt J Health Care. 2018; 9(2):75-86. https://doi.org/10.21608/ejhc.2018.10684

59. Kalakattawi RM, Kalakattawi AM, Alsuqati FA, et al. Risk of obstructive sleep Apnea (OSA) assessment among patients with type 2 diabetes in Taif, Saudi Arabia. J Basic Clin Pharma. 2018;9(12):68-72. https://doi.org/10.14740/ jocmr3189w

60. Awad KS, Aljarousha MA. Comparison of dry eye parameters between keratoconus patients and control subjects in Gaza strip, Palestine. IUGNES. 2017;25(2) 325-328.

61. El Sawy NN, Mahmoud DA, Madbouly WA. Evaluation of meibomian glands dysfunction in type two diabetic patients. Egypt J Hosp Med. 2019;77(2): 4982-4986. https://doi.org/10.12816/ejhm.2019.47986

62. Abusharaha A, Alturki AA, Alanazi SA, et al. An assessment of the tear evaporation rate in thyroid gland patients. Clin Ophthalmol. 2019;13:131-135. https://doi. org/10.2147/OPTH.S188614

63. Alanazi SA. Assessment of ocular tear film stability in subjects with high total cholesterol levels. Med J Cairo Univ. 2019;87:3109-3116. https://doi.org/10. 21608/mjcu.2019.59514

64. Masmali AM, Maeni YA, El-Hiti GA, Murphy PJ, Almubrad T. Investigation of ocular tear ferning in controlled and uncontrolled diabetic subjects. Eye Contact Lens. 2018;44(Suppl 2):S70-S75. https://doi.org/10.1097/ICL.0000000000000419

65. Kamel S, Mohammed T, El Zankalony $Y$, et al. Prevalence of dry eye in diabetics. J Egypt Ophthalmol Soc. 2017;110(3):77-82. https://doi.org/10.4103/ejos ejos_19_17

66. Elnour MAA, Saleh AA, Kalantan MM, et al. The relationship between coffee intake, obstructive sleep apnea risk, and type 2 diabetes glycemic control, in Tabuk City, The Kingdom of Saudi Arabia: A case-control study. BMC Res Notes. 2019;12(1):798. https://doi.org/10.1186/s13104-019-4838-3

67. Bashir S, Yousef M. Ocular ultrasound for evaluation of eye diseases amons hypertensive patients with long term of diabetes. IOSR J Dental Med Sci. 2020;19(3):23-28. 
68. Alghamdi AH. A descriptive retrospective study of ophthalmic care during pregnancy at Al Baha Province, Saudi Arabia. Int J Med Sci Public Health. 2018;7(11):922-927. https://doi.org/10.5455/ijmsph.2018.0823530082018

69. Ahmed MM, Saad NE, Almehelmy EM, Yousef FF. Computer vision syndrome and associated factors among students of Faculty of Medicine, Cairo University. Med J Cairo Univ. 2019;87(7):4877-4881. https://doi.org/10.21608/mjcu.2019. 85230

70. Khalil HEM, Aboud SA, Azzab MA. Comparative study between smokers and nonsmokers regarding dry eye. Delta J Ophthalmol. 2018;19(1):9-13. https://doi. org/10.4103/DJO.DJO_25_17

71. Alanazi SA, Abusharha A, Fagehi R, et al. Assessment of the tear evaporation rate in chronic smokers using delfin vapometer. Int J Ophthalmol Vis Sci. 2019;4(2): 37-41. https://doi.org/10.11648/j.ijovs.20190403.13
72. Alanazi SA. Assessment of tear film in subjects with a high body mass index. Clin Optom. 2019;11:77-84. https://doi.org/10.2147/OPTO.S218109

73. Elagamy A, Bawazir S. Dry eye evaluation in Saudi patients with vitamin D deficiency. J Ophthalmol Eye Care. 2019;2(1):105.

74. Alharthi F, Masoodi I, Alomairi N, Almuntashiri A, Alfaifi A. The predictor of obstructive sleep apnea at a high altitude: Results of a population-based study in the Western region of Saudi Arabia. Egypt J Hosp Med. 2018;73(1) 5818-5827.

75. Ali NM, Hamied FM, Farhood QK. Corneal thickness in dry eyes in an Iraqi population. Clin Ophthalmol. 2017;11:435-440. https://doi.org/10.2147/OPTH.S119343

76. Fagehi R, Ghazal H, Alrabiah S, et al. Ocular dryness assessment in Saudi employees working indoors and outdoors. Clin Optom. 2018;10:51-56. https:// (10.0147/OPTO S163303 